\title{
Anomalously large gradients in the "GEODATA 9 SECOND" Digital Elevation Model of Australia, and their effects on gravimetric terrain corrections
}

\author{
J. F. Kirby \\ W. E. Featherstone
}

Large gradients, when calculated by a first-difference method, have been detected in the 9 arc-second National Digital Elevation Model (DEM) of Australia released by the Australian Surveying and Land Information Group. Gradient values implied by the mean elevations in the DEM between adjacent grid cells of up to $74^{\circ}$ have been observed, most notably in Australia's more mountainous regions in the east. Comparisons with topographic maps indicate that these are anomalous gradients in the DEM that are not present in the actual topography. It is recommended that the first-difference method is used to test DEMs before they are used to compute terrain corrections.

\author{
Jon Kirby \\ Will Featherstone \\ Department of Spatial Sciences \\ Curtin University of Technology \\ GPO Box U1987 \\ Perth 6845 \\ Western Australia
}

\section{INTRODUCTION}

In 1996, the Australian Surveying and Land Information Group (AUSLIG) released a digital elevation model (DEM) of Australia on a regular 9 arcsecond grid: the GEODATA 9 SECOND DEM (e.g., Carrol and Morse, 1996). This grid spacing corresponds to approximately $250 \mathrm{~m}$ at $27^{\circ}$ latitude, a very high resolution considering the size of the Australian landmass and availability of elevation data. One example of the many uses of the Australian DEM is the authors' use of the DEM in computing geophysical terrain corrections to observed gravity data (Kirby and Featherstone, 1999). The terrain corrected gravity data were then used in the computation of the AUSGeoid98 national geoid model (Featherstone et al., 2000).

The GEODATA 9 SECOND DEM was constructed from AUSLIG's database of over 5 million spot heights digitized from 1:100,000 maps; approximately 200,000 elevations from gravity observations in the Australian Geological Survey Organisation's (AGSO) database; and stream line data (Carrol and Morse, 1996). The data were gridded using a drainage-enforcing algorithm (Hutchinson, 1989). This procedure ensures that the resulting DEM 
has a sensible drainage pattern, but in doing so it adjusts elevations in the input data.

In their previous work (Kirby and Featherstone, 1999), the authors detected unreasonably large values of the terrain correction in certain regions of Australia. These were originally attributed to instabilities in the terrain correction algorithm. Here, it is suggested that these anomalies are due to very steep topographic gradients present in the GEODATA 9 SECOND DEM, in which gradients of up to $74^{\circ}$ over baselines of less than a kilometre were detected. These claims are supported by a quantitative analysis of the terrain correction versus topographic gradient. Hence, the purpose of this article is to make users of the DEM aware of the anomalously large gradients, as it is probable that they could adversely affect studies in other disciplines. The study does not comment upon the possible sources of errors in the DEM, though it is recommended that calculation of gradients are used as a quality control stage in the production and before the use of future Australian DEMs.

\section{THE AUSTRALIAN DIGITAL TERRAIN CORRECTION MODEL}

When determining the geoid from gravity data, the effect of the topographic masses must be considered. A Bouguer gravity anomaly computed in any area of varying topographic relief will have a reduced value due to the presence of the topographic mass. Thus, a correction for the terrain effect must be computed and added to the Bouguer anomaly. Historically, these terrain corrections were calculated by hand using topographic maps and "Hammer charts" (Hammer, 1939). This laborious process can be avoided, however, by the use of digital elevation models.

The method of gravimetric terrain effect computation from topographic data implements the approximate formula of Moritz (1968):

$$
C=\frac{1}{2} G \rho \iint \frac{\left(H_{0}-H_{r}\right)^{2}}{\ell_{0}^{3}} d x d y
$$

where: $C$ is the terrain correction, $G$ is the Newtonian gravitational constant; $\rho$ is the density of sub-surface rocks (usually taken to be $2670 \mathrm{~kg} \cdot \mathrm{m}^{-3}$ ); $H_{0}$ is the orthometric height of the computation point; $H_{r}$ is the orthometric height of the roving point in the double integral, which is performed over all points in the area of interest; and $\ell_{0}$ is the planar distance between the computation and roving points.

The above computational formula is particularly suited to elevations on a DEM, as the integral may be evaluated using the fast Fourier transform (FFT). This results in the rapid calculation of the terrain correction, even for datasets of the size of AUSLIG's 9"×9" DEM. However, of most relevance to this article is the fact that equation (1) involves a component due to the topographic gradient: a height difference divided by a horizontal distance. Thus, the magnitude of the terrain correction depends upon the variation, or ruggedness of the topography. 
In the computation of a 9" $\times 9$ " digital terrain correction model (DTCM) for Australia, Kirby and Featherstone (1999) detected excessively large terrain corrections in the more mountainous regions of Australia. While the maximum computed value was $273 \mathrm{mGal}$ (where $1 \mathrm{mGal}=10 \mu \mathrm{m} . \mathrm{s}^{-2}$ ), 6 data records had values above $200 \mathrm{mGal}, 66$ data records had values above $100 \mathrm{mGal}$, and 576 had values over $50 \mathrm{mGal}$.

Initially these were thought to be due to an instability in the Moritz (1968) formula documented by Martinec et al. (1996). However, communication with D. Smith (pers. comm., 1999) indicated that a $30 \times 30$ metre DEM in the US Rocky Mountains yielded no excessively large terrain corrections from the same Moritz (1968) formula. Elimination of further possible causes of error suggested that these errors in the DTCM were due to errors in the DEM, specifically excessively large topographic gradients.

By way of comparison, the AGSO data set of 28,000 terrain corrections over Tasmania was compared with the DTCM. The AGSO data were determined from topographic maps using the conventional Hammer (1939) method, thus providing independent control (in Tasmania at least) of the DTCM generated by the authors. The AGSO data have a maximum value of $38 \mathrm{mGal}$, although the mean of over 28,000 observations on the island is only $1 \mathrm{mGal}$, with a standard deviation of $1.5 \mathrm{mGal}$. Furthermore, of these observations, only ten had terrain corrections greater than $20 \mathrm{mGal}$, and only one had a value of more than $30 \mathrm{mGal}$. This illustrates the scarcity of very high terrain corrections, even in relief such as Tasmania's. It also suggests that terrain correction values computed from the national DEM are very likely to arise from errors in the DEM.

\section{WORLDWIDE EXAMPLES}

The following examples show the magnitude of terrain corrections expected from different relief types. It must be noted that the quoted values are all band-limited, in that they omit the contribution from topographic sources very close to the gravity meter. However, as a band-limitation also applies to the Australian DTCM (which does not include information from sources less than half the DEM cell size - $125 \mathrm{~m}$ - from the computation point), a comparison between the Australian DTCM and the examples is reasonable.

In an FFT analysis conducted by Forsberg (1985) the terrain corrections in an area of eastern Greenland assumed a maximum value of $10 \mathrm{mGal}$, with a mean value of $3 \mathrm{mGal}$. A topographic contour map of a $100 \times 100 \mathrm{~m}$ DEM indicated that the terrain height in the region varied from 300 to $900 \mathrm{~m}$ with a maximum gradient of approximately $20^{\circ}$. However, in a study of New Mexico (Forsberg, ibid.), the maximum terrain correction was found to be $33 \mathrm{mGal}$, with a mean value of only $1 \mathrm{mGal}$. This area is predominantly flat, though the elevations vary from $1200 \mathrm{~m}$ to $2400 \mathrm{~m}$ on several steep mesas, with gradients present in the topography of up to approximately $35^{\circ}$ (again estimated from supplied contour maps). 
Another analysis of terrain corrections from a DEM was conducted over Mauna Kea in Hawaii by Smith (1992), where the mountain rises from sea level to over $4000 \mathrm{~m}$. Computations on a 3 arc-second grid (approximately 90 $\mathrm{m}$ cell size) yielded a maximum terrain correction of $75 \mathrm{mGal}$, with a mean value of $6 \mathrm{mGal}$. When the computations were performed on a 30 arc-second grid (approximately $900 \mathrm{~m}$ cell size), a maximum terrain correction of $58 \mathrm{mGal}$ with a mean value of $8 \mathrm{mGal}$ was seen. And when computed on a 2 arcminute grid (approximately $3.7 \mathrm{~km}$ cell size), a maximum terrain correction of $50 \mathrm{mGal}$ with a mean value of $6 \mathrm{mGal}$ resulted.

Finally, terrain corrections were derived through the FFT method by Li and Sideris (1994) in an area of the Canadian Rockies where the topography varied from sea level to $3573 \mathrm{~m}$. Computations performed on a $100 \times 100 \mathrm{~m}$ DEM returned terrain corrections with a maximum value of $43 \mathrm{mGal}$ and a mean value of $5 \mathrm{mGal}$. When the computations were performed on a $1100 \times 1100 \mathrm{~m}$ grid, the terrain corrections had a maximum value of $17 \mathrm{mGal}$, with a mean of $3 \mathrm{mGal}$.

From these studies, it can be seen that as the DEM resolution increases, the maximum value of the derived terrain correction increases, with a maximum quoted value of $75 \mathrm{mGal}$ on a $90 \mathrm{~m}$ grid. This is to be expected since averaging the relief into larger cells will generally smooth the topographic surface, and omit near-meter effects.

While the above examples are by no means exhaustive, they do include areas of extreme topography represented by high-resolution DEMs. Hence, as no information could be found concerning terrain correction studies in areas such as the Himalayas or Andes, it is suggested that terrain corrections worldwide will probably not exceed the quoted values by considerably large amounts, and certainly not exhibit values such as the $273 \mathrm{mGal}$ seen in the Australian DTCM.

\section{COMPUTING THE GRADIENT FROM THE DEM}

The gradient of the DEM was determined by a simple first-difference formula, rather than more complex surface-fitting algorithms (e.g., Besl, 1988). Although the latter more faithfully reproduce an average gradient and terrain shape, they smooth out the finer detail desired for this study. Moreover, though discouraged by Besl (ibid.), computation of the gradient of a DEM through direct numerical differentiation is absolutely necessary if irregularities in the DEM are to be compared with the terrain correction as calculated by equation (1).

The analysis proceeded in two stages. The first stage entailed a direct computation of the gradient between adjacent cells in the GEODATA 9 SECOND DEM, in the east, north and north-east directions. This was achieved by application of the formula: 


$$
\beta=\tan ^{-1}\left(\frac{\Delta H}{\ell_{0}}\right)
$$

where $\beta$ is the gradient in degrees, $\Delta H$ is the difference in elevation between the adjacent cells, and $\ell_{0}$ is the planar distance between the centres of the cells.

The second stage involved a comparison of the DEM-implied gradient with the terrain correction, to determine whether large terrain corrections were spatially correlated with large gradients. As a preliminary step in this analysis, records in the 9" $\times 9$ " DTCM were written to seven files depending upon their terrain correction value. One file was created for terrain corrections in the band $20-29 \mathrm{mGal}$, another file for $30-39 \mathrm{mGal}$, and so on for bands of $40-$ 49, 50 - 74, 75 - 99, 100 - 199, and 200 - 299 mGal. Computing and analysing DEM gradients from the coordinates of records in these bands would distinguish the results for low, medium and high terrain corrections. Hence, for each record in these files, a gradient in degrees between the terrain correction record location and each DEM node within a $1 \mathrm{~km}$ search radius was computed, using the algorithm:

$$
\beta=\tan ^{-1}\left(\frac{\bar{H}_{0}-\bar{H}_{r}}{\ell_{0}}\right)
$$

where $\bar{H}_{0}$ is the mean elevation of the computation point (i.e., the DEMimplied height of a single record in a terrain correction file, the DEM and DTCM being on the same grid), and $\bar{H}_{r}$ is the mean elevation of the roving point within the search radius.

When using the mean elevations implied by the AUSLIG DEM, it is expected that the gradient, $\beta$, will have a smaller value than in reality, due to the smoothing of topography in the averaging process. Hence, any anomalously large gradients will be significant.

\section{RESULTS AND DISCUSSION}

The first stage of the work, direct computation of gradients from the GEODATA 9 SECOND DEM, yielded 348 gradients with values above $60^{\circ}$. The locations of these gradients are shown in Figure 1. Of these, 11 gradients had values over $70^{\circ}$. The maximum gradient computed in this fashion was $74^{\circ}$. 


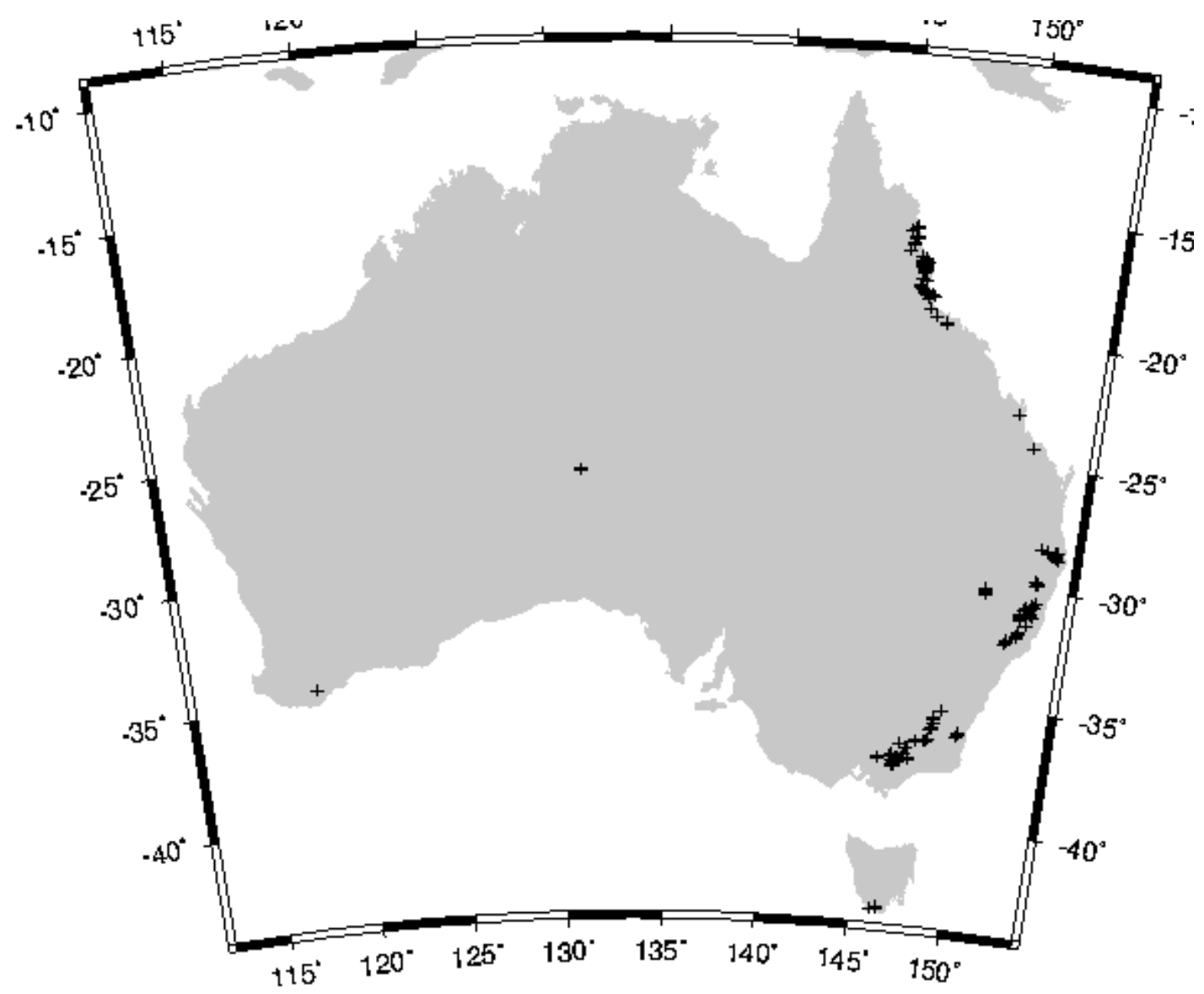

Figure 1. Locations of gradients greater than $60^{\circ}$ in the GEODATA 9 SECOND DEM. Lambert conical projection.

Concerning the second stage of the research, the statistics derived from the gradients within each of the seven bands are shown in Table 1. The first column records the terrain correction band values and the second column the number of records in each band. To arrive at the figures in the third column, of all the gradients computed within the $\ell_{0}=1 \mathrm{~km}$ search radius for a particular terrain correction record, the maximum gradient was selected. This procedure was performed on all records in the band, and the mean value taken and recorded in column $3\left(\bar{\beta}_{\max }\right)$. Column 4 shows the standard deviation of these maximum gradients $\left(\sigma_{\beta \max }\right)$.

The third column in Table 1 shows the mean of the maximum gradients for each terrain correction point rather than the mean of all gradients because of the diminishing value of gradient with distance in equation (3). There are more points towards the outer parts of the $1 \mathrm{~km}$ search radius, and these points generally return a smaller gradient. Hence, they would down-weight a mean value of all gradients, thus swamping the large values of gradient close to the computation point that are of interest to this study. 


\begin{tabular}{|c|c|c|c|}
\hline $\begin{array}{c}\text { Band } \\
\text { (mGal) }\end{array}$ & $\begin{array}{l}\text { No. TC } \\
\text { records }\end{array}$ & $\begin{array}{c}\overline{\boldsymbol{\beta}}_{\max } \\
\text { (degrees) }\end{array}$ & $\begin{array}{c}\sigma_{\beta \max } \\
\text { (degrees) }\end{array}$ \\
\hline $20-29$ & 6084 & 33 & 9.5 \\
\hline $30-39$ & 1532 & 37 & 9.2 \\
\hline $40-49$ & 536 & 38 & 8.9 \\
\hline $50-74$ & 411 & 42 & 8.8 \\
\hline $75-99$ & 102 & 45 & 6.9 \\
\hline $100-199$ & 61 & 48 & 6.8 \\
\hline $200-299$ & 7 & 57 & 2.3 \\
\hline
\end{tabular}

Table 1. The mean and standard deviation of the maximum gradients, as computed for the records in each of seven terrain correction bands.

The same is also true of terrain corrections: a large mountain close to the computation point has a much larger terrain effect than the same mountain placed further away. This influenced the (arbitrary) choice of $1 \mathrm{~km}$ for the search radius. The anomalous terrain correction values in the DTCM are most likely to be caused by anomalous gradients in the DEM very close to the computation point, within one or two grid cells. On a $250 \mathrm{~m}$ grid, $1 \mathrm{~km}$ represents 4 cells.

The data in Table 1 support the thesis that anomalous terrain corrections in the DTCM are due to excessive gradients in the DEM. When a given band is compared with its predecessor in Table 1, the mean gradient value increases significantly with increasing terrain correction, as tested using the normal and t-distributions at the $99.5 \%$ confidence level. Furthermore, the spread of these maxima (measured by the standard deviation in column 4) decreases. This indicates that the large gradients recorded in the higher bands are consistently steep. The terrain correction is a cumulative quantity: the presence of only one large gradient in the DEM will generate a smaller terrain correction than many slightly smaller gradients. Hence, a lower variability of high gradients will yield a higher terrain correction than a more diverse range of lower values of the gradient, as present in the lower bands.

With regard to each gradient computed within the $1 \mathrm{~km}$ search radius (i.e., before averaging), a maximum value of $74^{\circ}$ was returned, in keeping with the result from the first stage. Indeed, 18 of the 493,832 gradient values computed in this stage returned values over $70^{\circ}$. While such steep gradients could be observed in the Australian topography on a very local scale, the values computed in this study represent an average gradient in that they are determined from 9" $\times 9$ " cells over which the topography has been averaged and smoothed. The fact that large mean gradients occur reinforces the case for anomalously large gradients in the DEM.

Figure 2 shows the locations of cells with a value of the terrain correction of $75 \mathrm{mGal}$ or greater. At this scale, the similarity between Figures 1 and 2 is striking. To clarify this spatial correlation, Figure 3 shows those terrain correction records in Figure 2 that are within four grid-cells $(1 \mathrm{~km})$ of a large 
gradient value (the crosses in Figure 1). As there are 378 gradient points in Figure 1, 170 terrain correction points in Figure 2, and 138 terrain correction points in Figure 3, this means approximately $81 \%$ of the anomalous terrain correction records (greater than $75 \mathrm{mGal}$ ) are within four grid-cells of a gradient of $60^{\circ}$ or more in the DEM.

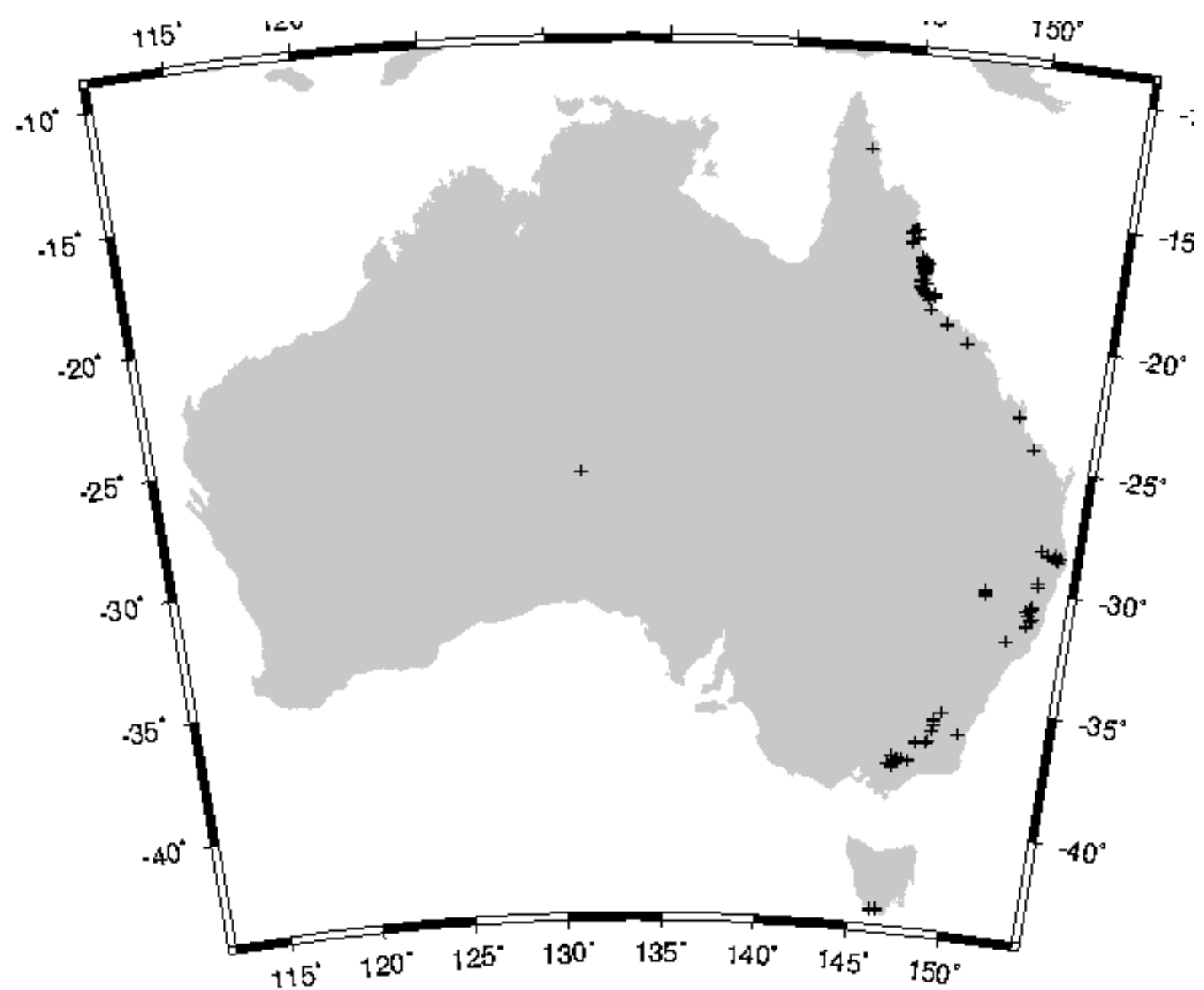

Figure 2. Locations of terrain corrections greater than $75 \mathrm{mGal}$ in the 9 " $\times 9$ " DTCM. Lambert conical projection. 


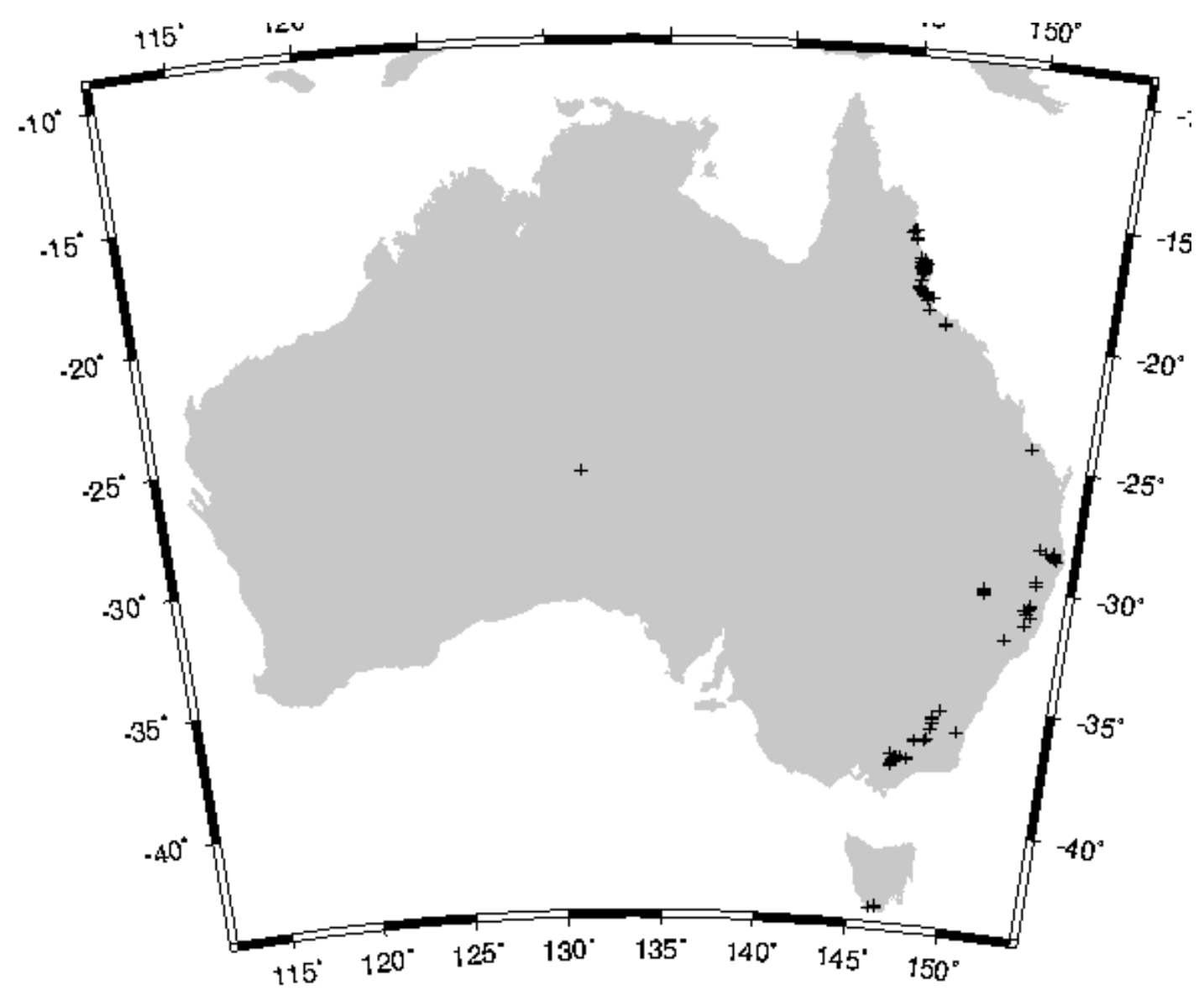

Figure 3. Locations of spatially coincident values of the data in Figures $1 \& 2$. Lambert conical projection.

The correlation is shown in greater detail in Figure 4, this being an enlargement of part of the data cluster in the north coast area of Queensland, over the area $17^{\circ} 0^{\prime}$ to $17^{\circ} 30^{\prime}$ south latitude and $145^{\circ} 42^{\prime}$ to $146^{\circ} 0^{\prime}$ east longitude. Values of the gradient in excess of $70^{\circ}$ and values of the terrain correction greater than $200 \mathrm{mGal}$ are to be found exclusively in this area. In Figure 4, the circles represent grid cells with a gradient of $60^{\circ}$ or more, while the crosses represent cells with a terrain correction of $75 \mathrm{mGal}$ or more. These symbols are plotted on a greyscale image of the 9" $\times 9$ " DEM, which has a maximum elevation of $1583 \mathrm{~m}$. In the majority of cases, the circles and crosses are almost coincident. Again, this illustrates that anomalously large DEM gradients are causing the terrain corrections to be too large. 


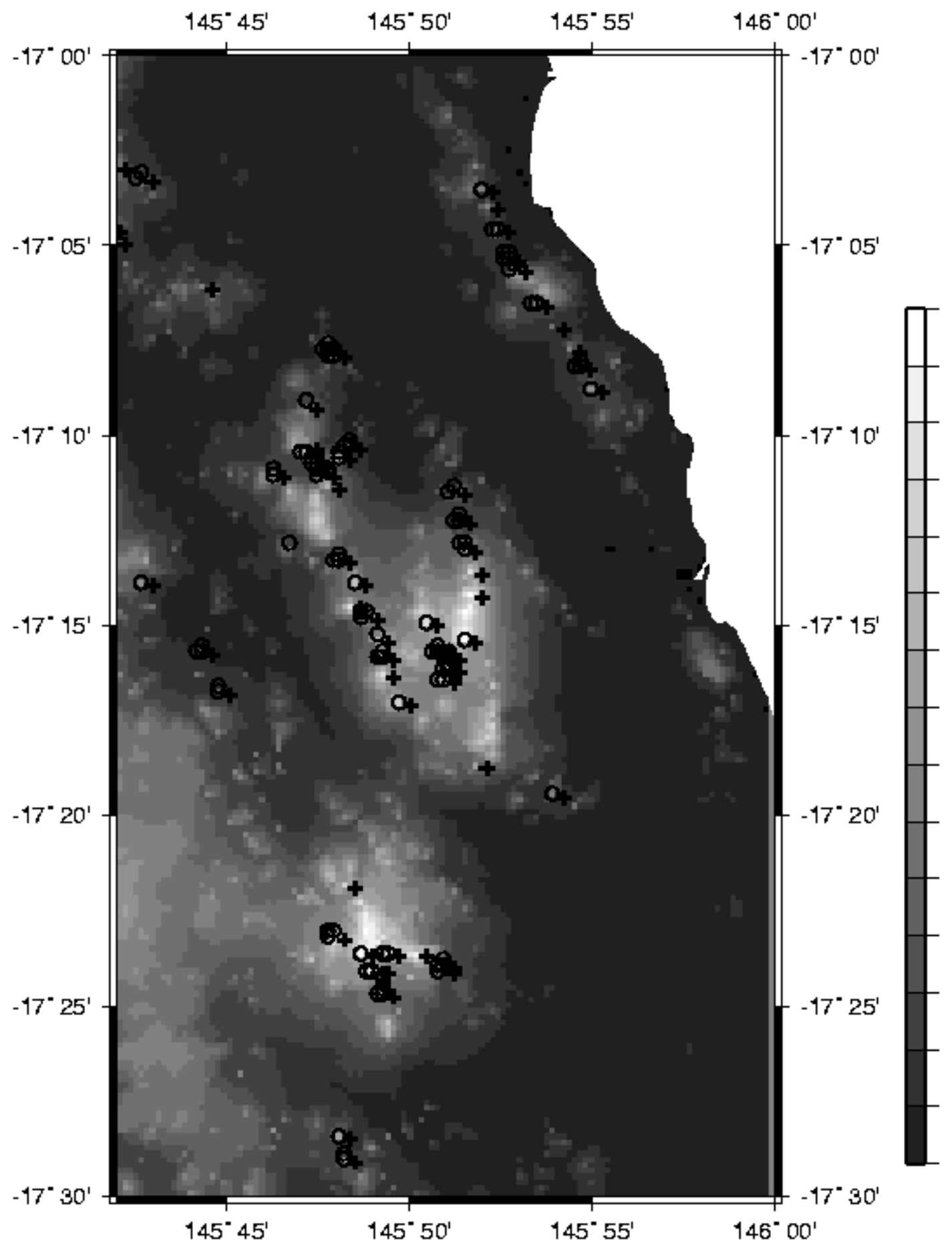

Figure 4. Gradient $>60^{\circ}$ (circles) and terrain correction $>75 \mathrm{mGal}$ (crosses), plotted on the GEODATA 9 SECOND DEM over an area centred on the Bellenden Kerr Range, Queensland. Units in metres. Mercator projection. 
To verify this correlation, topographic gradients were determined by direct measurement from a topographic map of the area shown in Figure 4 (sheet SE55-06, Innisfail, at 1:250,000 scale). Three clusters of circles and crosses can be seen in the figure: on the Malbon Thompson Range in the north, the Bellenden Kerr Range in the centre, and Bartle Frere to the south. The highest gradient determined from the map occurrs in the western flanks of the Bellenden Kerr Range, with a value of approximately $40^{\circ}$ (the error on this measurement is estimated at approximately $7^{\circ}$ ).

This value of $40^{\circ}$ appears to be among the highest in the Australian topography. In their analysis of the GEODATA 9 SECOND DEM, Carrol and Morse (1996) took the map sheet containing Mount Kosciusko to estimate the errors in the DEM due to very rugged terrain. The relief in this region was found to have a root mean square gradient of only $11^{\circ}$, which generated a maximum overall DEM elevation error of $43 \mathrm{~m}$. However, they estimate that errors in the model will approach $90 \mathrm{~m}$ for local gradients of $45^{\circ}$. These gradient values are considerably less that the gradients of over $70^{\circ}$ determined in the presented paper. Again, this suggests that the DEM contains anomalously large gradients.

\section{CONCLUSIONS}

Exceptionally large values of the topographic gradient have been detected in the GEODATA 9 SECOND DEM of Australia. These were first discovered (unwittingly) through use of the DEM when computing gravimetric terrain corrections for geoid computation. However it was (probably incorrectly) attributed to the instability in the Moritz algorithm. The terrain correction is calculated with an equation similar to the one used for computing mean gradients, and application of this equation to the DEM resulted in unreasonably large values of the terrain correction. After eliminating other potential sources of error, gradients in the DEM were analysed, and were found to return values in excess of $60^{\circ}$, and sometimes up to $74^{\circ}$.

While the AGSO terrain correction data in Tasmania indicate that the maximum value is $38 \mathrm{mGal}$, we do not have such independent control of the high terrain correction values along the east coast of Australia. However, terrain correction values of $75 \mathrm{mGal}$ or greater are very uncommon in the world, and are not seen even in places such as the Rocky Mountains and Hawaii. Hence, we can assume with some degree of confidence that the anomalous terrain corrections in the Great Dividing Range are artificially generated by anomalous gradients in the DEM. This assumption is borne out by the results of this research, notably the proximity of large terrain correction values and large gradients, the confidence tests of terrain correction magnitude versus gradient, and most importantly, by comparisons with topographic maps.

The solution in this instance has been to generalise the 9" $\times 9$ " DEM to a 27 " $\times 27$ " grid in order to smooth the DEM, but this omits near-meter effects in 
the terrain correction, and is not ideal. Hence, it is recommended that future models should be analysed for steep gradients in the presented fashion. This, for example, will ensure that reliable gravimetric terrain corrections can be computed while exploiting the full resolution of the national DEM.

\section{ACKNOWLEDGEMENTS}

The authors would like to thank Dr Dru Smith of the US National Geodetic Survey for discussions that initiated this study of the Australian DEM, AUSLIG for supply of the national GEODATA 9 SECOND DEM, and the reviewers of this paper.

\section{REFERENCES}

Besl, P.J. (1988). Surfaces in Range Image Understanding, Springer-Verlag, New York.

Carrol, D. and M. P. Morse (1996). A national digital elevation model for resource and environmental management, Cartography, 25, 395-405.

Featherstone, W.E., J.F. Kirby, A.H.W. Kearsley, J.R. Gilliland, G.M. Johnston, J. Steed, R. Forsberg, and M.G. Sideris (2000). The AUSGeoid98 geoid model of Australia: data treatment, computations and comparisons with GPS-levelling data, Journal of Geodesy, in press.

Forsberg, R. (1985). Gravity field terrain effect computations by FFT, Bulletin Geodesique, 59, 342-360.

Hammer, S. (1939). Terrain corrections for gravimeter stations, Geophysics, 4, 184-194.

Hutchinson, M.F. (1989). A new procedure for gridding elevation and stream line data with automatic removal of spurious pits, Journal of Hydrology, 106, 211-232.

Kirby, J.F. and W.E. Featherstone (1999). Terrain correcting Australian gravity observations using the national digital elevation model and the fast Fourier transform, Australian Journal of Earth Sciences, 46, 555-562.

Li, Y.C. and M.G. Sideris (1994). Improved gravimetric terrain corrections, Geophysical Journal International, 119, 740-752.

Martinec, Z., Vanicek, P., Mainville, A. and Veronneau, M. (1996). Evaluation of topographical effects in precise geoid computation from densely sampled heights, Journal of Geodesy, 70, 746-754.

Moritz, H. (1968). On the use of the terrain correction in solving Molodensky's problem, Department of Geodetic Science and Surveying, Ohio State University Report 108.

Smith, D.A. (1992). The use of high resolution height data in the computation of high precision geoid undulations on the island of Maui, Department of Geodetic Science and Surveying, Ohio State University Report 424.

Smith, D.A. (1999). NOAA, National Geodetic Survey, 1315 East-West Hwy, Silver Spring, MD 20910. U.S.A. 